\title{
Potentials and limitations of footprints for gauging environmental sustainability
}

\author{
Laurent, Alexis; Owsianiak, Mikolaj
}

Published in:

Current Opinion in Environmental Sustainability

Link to article, DOI:

10.1016/j.cosust.2017.04.003

Publication date:

2017

Document Version

Peer reviewed version

Link back to DTU Orbit

Citation (APA):

Laurent, A., \& Owsianiak, M. (2017). Potentials and limitations of footprints for gauging environmental sustainability. Current Opinion in Environmental Sustainability, 25, 20-27.

https://doi.org/10.1016/j.cosust.2017.04.003

\section{General rights}

Copyright and moral rights for the publications made accessible in the public portal are retained by the authors and/or other copyright owners and it is a condition of accessing publications that users recognise and abide by the legal requirements associated with these rights.

- Users may download and print one copy of any publication from the public portal for the purpose of private study or research.

- You may not further distribute the material or use it for any profit-making activity or commercial gain

- You may freely distribute the URL identifying the publication in the public portal

If you believe that this document breaches copyright please contact us providing details, and we will remove access to the work immediately and investigate your claim 


\title{
Potentials and limitations of footprints for gauging
}

\section{environmental sustainability}

\author{
Alexis Laurent*, Mikołaj Owsianiak \\ Division for Quantitative Sustainability Assessment, Department of Management Engineering, \\ Technical University of Denmark, 2800 Kgs. Lyngby, Denmark \\ * To whom correspondence should be addressed: $\underline{\text { alau@dtu.dk }}$
}

\begin{abstract}
To address the sustainability challenge, a large variety of footprints, aiming at capturing specific impacts of human activities on natural environment, have emerged. But, how do they fit into our addressing of environmental sustainability? Here, we build on a critical literature review to (1) provide an overview of existing footprints; (2) define their roles; (3) position them within the broad spectrum of known environmental problems and control variables of the planetary boundaries; and (4) argue for the need of consistent thresholds to benchmark footprint scores against absolute sustainability measures defined using science-based sustainability targets. Potentials, limitations and research needs are highlighted along these four points.
\end{abstract}


Laurent A., Owsianiak M., 2017. Potentials and limitations of footprints for gauging environmental sustainability. Current Opinion in Environmental Sustainability 25, 20-27. DOI: https://doi.org/10.1016/j.cosust.2017.04.003

\section{Graphical abstract}

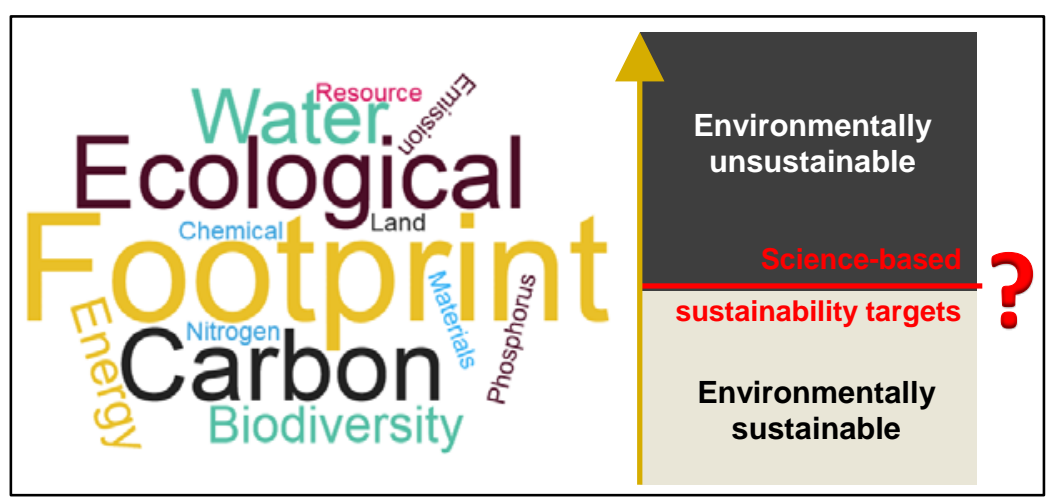




\section{On-going development of footprints}

Human activities are globally unsustainable, causing several environmental impacts, such as climate change and resource depletion, and jeopardizing the safe operating space for humanity [1,2]. Over the past 2 decades, international and national initiatives, including the recently-released United Nations Sustainable Development Goals (SDG), have emerged to address this sustainability challenge and called for the development of methods, tools and indicators for specifically assessing environmental sustainability [3]. Environmental sustainability has commonly been defined by the output/input rule, i.e., "keeping waste emissions within assimilative capacities, harvesting within regenerative capacities of renewable resources, and depleting non-renewables at the rate at which renewable substitutes are developed” [4,5].

Among prominent tools to address environmental sustainability are so-called footprinting tools, which emerged in the 90s with the development of the ecological footprint and, later on, of the carbon footprint [6-9]. The large recognition of these stand-alone indicators by industries, authorities and non-governmental stakeholders and their relative simplicity in communicating results have made them increasingly used and led them to shape many current debates on environmental sustainability in our societies [1,10-12]. Following these two footprints, other footprints have been developed, sharing the same features of addressing a specific environmental concern and quantifying the resource appropriation (e.g. use of land or water; [13]) and/or waste generation (e.g. emissions of $\mathrm{CO}_{2}$ ) associated with given human activities [1,14,15]. How does this suite of existing footprints fit into our needs for effectively addressing environmental sustainability? Recent studies have exhaustively reviewed the use of footprints, among which Čuček et al. [15] and Fang et al. [14,16-18] can be regarded as the most advanced ones. Albeit with different scoping, the studies by Čuček et al. [15] and Fang et al. [14,16] provided a comprehensive overview of existing footprints, either addressing environmental, economic and/or social dimension of sustainability [15] or just environmental issues [14,16], and reviewed their definitions, assessment scoping and 
methodological practice. Fang et al. $[17,18]$ went further and explored the linkage of environmental footprints with thresholds defined by planetary boundaries to derive a framework for environmental sustainability assessment. The definition of planetary boundaries aims to define a "safe operating space for humanity”, i.e. globally- and/or regionally-sustainable space that should not be exceeded to prevent abrupt and irreversible changes in Earth system like global climate [2,19]. None of these past studies critically related the suite of existing footprints to their ability to cover all known environmental issues, nor did they critically gauge the limitations of the metrics from the planetary boundary framework to serve as thresholds for footprints.

Building on up-to-date literature and recent scientific advances, we therefore aim to (1) critically review existing footprinting tools; (2) position them with regard to a comprehensive mapping of damages to ecosystems and human health as commonly assessed in life cycle assessment (see next section); and (3) clarify their roles and limitations when addressing environmental sustainability, particularly in relation to the development of consistent and scientifically-sound thresholds and the possible utilisation of the planetary boundary framework.

\section{Definition and overview of existing footprints}

A large variety of footprints addressing environmental issues currently exists. Table 1 provides an overview of these, covering footprints that are named as such by their authors and have a generic focus on environmental interventions, i.e. flows drawn from the environment without previous human transformation (e.g. land, water, metal ores, etc.) and outputs released to the environment without subsequent human transformations (e.g. emissions of substances to air, water and soil) [20]. Footprints that are named after the activities or sectors which they assess, e.g. FOODPrint $[21,22]$ or the EU-developed Product and Organisation Environmental Footprint [23], are therefore not explicitly listed here; they however usually rely on the footprints listed in Table 1 in their 
assessment or on related tools such as the more broadly-encompassing life cycle assessments (LCA).

LCA is a methodology, which aims to quantify a broad range of environmental impacts caused by pollutant emissions and resource consumptions (environmental interventions) stemming from the life cycle of products or systems, i.e. from extraction of raw materials through production and use or operation of products/systems up to their disposal stage [24,25]. Several footprints can thus be considered subsets of LCA, i.e. LCA studies truncated to addressing single environmental issues. This is for example the case of carbon footprint and water footprint (as defined in ISO14046, 2014; [26]), which are the only ISO-standardised footprints and largely borrow their assessment methodologies from LCA practice, including the consideration of a life cycle perspective [26-29]. Despite these important connections, some debates have emerged about the positioning of the families of footprints with regard to LCA and the nature of their relationships [30-33]. As part of the UNEP/SETAC Life Cycle Initiative project on environmental life cycle impact assessment (LCIA), a task force has recently acknowledged the different purposes of footprints and LCA, which should be regarded as complementary tools [34]. While footprints aim to inform society and non-technical stakeholders on specific environmental problems, LCA addresses stakeholders wishing to comprehensively assess environmental performances and identify environmental tradeoffs. In light of this distinction, Ridoutt et al. defined footprints as metrics to report LCA results addressing a specific area of concern, i.e. an environmental topic defined by the interest of society, for example global warming (carbon footprint), water resource depletion (scarcity water footprint) or biodiversity threats (biodiversity footprint) [31].

To enable communication to a broad variety of stakeholders, e.g. public opinion, industrial stakeholders, policy-makers or regulators, footprints may require applications at different levels ranging from individuals or single products through companies or sectors to large geographical areas such as cities, nations or the world as a whole [1]. Most existing footprints currently enable 
Laurent A., Owsianiak M., 2017. Potentials and limitations of footprints for gauging environmental sustainability. Current Opinion in Environmental Sustainability 25, 20-27. DOI: https://doi.org/10.1016/j.cosust.2017.04.003

such multi-focus assessments, e.g. carbon, blue water scarcity footprints, and some of them benefit from ISO standards specifying a harmonised assessment methodology (carbon footprint: ISO14064, ISO14067 [27,28]; water footprint: ISO14046 [26]; see Table 1).

Tracking the environmental flows or impacts contributing to the footprint scores, i.e. identifying what the largest causes of emissions, resource consumptions and/or associated impacts are, is often an additional purpose of footprinting. Footprints typically adopt a consumption-based perspective, attempting to link the consumption patterns and lifestyles within a given area to the resulting impacts or emissions or resource extractions in other locations of the world. This can be facilitated by the use of multi-regional input-output (MRIO) models, which have gained momentum over the past decade for large-scale assessments, e.g. at national and global scales, and are used in material footprint and biodiversity footprints (see Table 1) as well as in more established footprints, like nations' carbon footprint (e.g. ref. [35]) or water footprint (e.g. ref. [36]). Using those models, Lenzen et al. and Moran et al. thus demonstrated that consumption patterns in developed countries, like in Europe, drove specific biodiversity threats in developing countries through their imports $[37,38]$. Further research to allow the use of MRIO models for other large-scale footprint purposes (e.g. chemical footprint) and, more generally, to derive consistent frameworks and methods for existing and new footprints are still required (see also next section).

Table 1. Overview of existing footprints

\begin{tabular}{|c|c|c|c|c|}
\hline Name & Environmental problems addressed $^{a}$ & Standards & $\begin{array}{l}\text { Overall } \\
\text { use }^{\text {b }}\end{array}$ & $\begin{array}{l}\text { Suggested } \\
\text { references }^{c}\end{array}$ \\
\hline $\begin{array}{l}\text { Carbon } \\
\text { footprint }\end{array}$ & $\begin{array}{l}\text { Focus on climate change impacts, quantifying changes in radiative forcing } \\
\text { caused by emissions of the } 7 \mathrm{GHGs}\left(\mathrm{CO}_{2}, \mathrm{CH}_{4}, \mathrm{~N}_{2} \mathrm{O}, \mathrm{PFCs}, \mathrm{HFCs}, \mathrm{SF}_{6} \text {, }\right. \\
\mathrm{NF}_{3} \text { ) framed by Kyoto Protocol }[9,27,28,39] \text {. Emissions are typically } \\
\text { addressed in a life cycle perspective, including all stages of the systems } \\
\text { (from raw materials extraction to end-of-life). }\end{array}$ & $\begin{array}{l}\text { Yes (incl. } \\
\text { ISO) }{ }^{d}\end{array}$ & $\begin{array}{l}\text { Very } \\
\text { large }\end{array}$ & $\begin{array}{l}{[9,27,28,35,} \\
36,39]\end{array}$ \\
\hline $\begin{array}{l}\text { Ecological } \\
\text { footprint }\end{array}$ & $\begin{array}{l}\text { Focus on biocapacity, defined as the area of biologically productive space } \\
\text { required to produce consumed resources and to absorb generated waste } \\
\text { associated with given activities }[6-8,40] \text {. For nations/regions, the definition } \\
\text { has been extended to all land use required for population activities taking } \\
\text { place on the biosphere within a given year [14,41]. It is closely related to } \\
\text { land and energy footprints. }\end{array}$ & Yes $^{\mathrm{e}}$ & $\begin{array}{l}\text { Very } \\
\text { large }\end{array}$ & {$[6-8,40-42]$} \\
\hline
\end{tabular}


Laurent A., Owsianiak M., 2017. Potentials and limitations of footprints for gauging environmental sustainability. Current Opinion in Environmental Sustainability 25, 20-27. DOI: https://doi.org/10.1016/j.cosust.2017.04.003

\begin{tabular}{|c|c|c|c|c|}
\hline $\begin{array}{l}\text { Energy } \\
\text { footprint }\end{array}$ & $\begin{array}{l}\text { Subset of ecological footprint, originally defined as amount of forest area } \\
\text { required to absorb } \mathrm{CO}_{2} \text { emissions caused by fossil fuel combustion and } \\
\text { electricity generation [6,43]. Other definitions have been proposed, e.g. } \\
\text { aggregated areas used to provide non-food and non-feed energy [41]. }\end{array}$ & No & $\begin{array}{l}\text { Mediu } \\
\mathrm{m}\end{array}$ & {$[6,41,43]$} \\
\hline $\begin{array}{l}\text { Land } \\
\text { footprint }\end{array}$ & $\begin{array}{l}\text { Focus on areas required for specific activities, e.g. forest footprint (i.e. } \\
\text { forest area required for consumed forest products) or grazing land footprint } \\
\text { (i.e. land area used for livestock) [12]. See other examples in Čuček et } \\
\text { al.[15]. }\end{array}$ & No & Little & {$[12,15,36]$} \\
\hline $\begin{array}{l}\text { Water } \\
\text { footprint }\end{array}$ & $\begin{array}{l}\text { Several indicators and methodologies exist: } \\
\text { - Green and/or blue and/or grey water footprints defined as cumulative } \\
\text { virtual water content of products/services consumed by individuals, } \\
\text { organisations or countries [13] } \\
\text { - Water scarcity footprint, comparing water consumptions against } \\
\text { - respective water scarcity indices (e.g. ref. [26,44]) } \\
\text { - Water availability footprint, addressing water scarcity by also accounting } \\
\text { - for reduced availability due to water pollution (e.g. [26,45]) } \\
\text { - Water footprint, as defined in ISO } 14046 \text { [26], which addresses water } \\
\text { consumption and pollution through impact characterisation }\end{array}$ & $\begin{array}{l}\text { Yes (incl. } \\
\text { ISO) }\end{array}$ & Large & $\begin{array}{l}{[13,26,36,44} \\
-52]\end{array}$ \\
\hline $\begin{array}{l}\text { Materials } \\
\text { footprint / } \\
\text { Resource } \\
\text { footprint }\end{array}$ & $\begin{array}{l}\text { Focus on economically-used materials, quantifying the consumption of raw } \\
\text { materials pulled by a final demand in a life cycle perspective, with use of } \\
\text { multi-regional input-output (MRIO) models [53]. }\end{array}$ & No & Little & {$[36,53,54]$} \\
\hline $\begin{array}{l}\text { Nitrogen } \\
\text { footprint }\end{array}$ & $\begin{array}{l}\text { Focus on total amount of reactive nitrogen released to the environment as a } \\
\text { result of an entity's consumption patterns }[55,56]\end{array}$ & No & Little & [55-57] \\
\hline $\begin{array}{l}\text { Phosphorus } \\
\text { footprint }^{\mathrm{g}}\end{array}$ & $\begin{array}{l}\text { Focus on amount of mined phosphate required by a given } \\
\text { demand/consumption }[58,59]\end{array}$ & No & Little & \begin{tabular}{|l} 
[57-59] \\
\end{tabular} \\
\hline $\begin{array}{l}\text { Chemical } \\
\text { footprint }\end{array}$ & $\begin{array}{l}\text { - focus on the dilution capacity required to maintain safe concentrations } \\
\text { and prevent ecological damage from releases of chemicals to the } \\
\text { environment [60-62]. }\end{array}$ & No & Little & [60-63] \\
\hline $\begin{array}{l}\text { Biodiversity } \\
\text { footprint }\end{array}$ & $\begin{array}{l}\text { Several indicators and methodologies exist, including: } \\
\text { - Area required to compensate for the losses in mean species abundance } \\
\text { resulting from land use and carbon dioxide emissions associated with a } \\
\text { system life cycle [64]. } \\
\text { - Focus on quantifying biodiversity threats resulting from the expenditure } \\
\text { of a final consumer, by linking endangered and vulnerable species due to } \\
\text { anthropogenic threat causes with industrial sector activities via the use of } \\
\text { multi-regional input-output (MRIO) models [37,38] }\end{array}$ & No & Little & $\begin{array}{l}{[37,38,64,65} \\
]\end{array}$ \\
\hline $\begin{array}{l}\text { Emission } \\
\text { footprint }\end{array}$ & $\begin{array}{l}\text { Focus on total emissions to air, water and soil compartments from } \\
\text { products/services converted into area based on the requirements that } \\
\text { anthropogenic emissions shall not change the quality of the local } \\
\text { compartment }[15,66]\end{array}$ & No & Little & {$[15,66]$} \\
\hline
\end{tabular}

${ }^{a}$ Definitions and descriptions based on reviews by Fang et al. [14] and Čuček et al. [15], complemented by literature search. Most accepted definitions are provided, except in cases where several evenly-used ones exist. In those cases, references to literature sources for further details are provided.

b Flags defined to characterise the overall use are "little $<$ medium $<$ large $<$ very large". They are based on arbitrary judgement of the authors from knowledge of the use of footprints in scientific literature, corporations, authorities and non-governmental organisations.

${ }^{\mathrm{c}}$ List of suggested references not exhaustive.

d International level: ISO 14064 (corporations and projects; [27]), ISO 14067 (products; [28]); GHG Protocol Standards (Corporations, projects, products; http://ghgprotocol.org/standards); national level: PAS2050 [67], plus other national schemes.

e Ecological Footprint Standards 2009 [41]. 
${ }^{\mathrm{f}}$ ISO 14046 [26](ISO, 2014); Global Water Footprint Assessment Standard [13].

$\mathrm{g}$ “The term "Nutrient footprint” has also been suggested, capturing both nitrogen and phosphorus footprints (e.g. Grönman et al. [57]). However, authors also recommend to handle them individually because of differences in their respective environmental mechanisms [57].

\section{Limitations of existing footprints in covering environmental impacts}

A frequent criticism of footprints has been their narrow focus on a specific environmental concern, thus missing out other environmental problems. Taking the footprint definition by Ridoutt et al. (see previous section; [31]), this is however not a limitation per se as footprints target these specific environmental concerns on purpose (in line with a societal context). However, the risk is high that researchers and stakeholders misunderstand and/or inadvertently misuse footprinting results. An unfortunately large number of studies in the scientific literature and in popular media evidence occurrences of such situations, for example the many studies using carbon footprint results to support claims about “environmental sustainability”, “low environmental burden”, "green products” or "environmental friendliness".

Studies have however showed that stand-alone footprints, e.g. carbon footprint or ecological footprint, cannot act as acceptable proxies for systematically capturing the broad spectrum of environmental problems, thus making those claims inappropriate (see, e.g., ref. [40,68,69]). Stakeholders using footprints should therefore take great care to remain consistent with the purpose of their assessment and not to overstate their conclusions. If the purpose of the assessment is to comprehensively evaluate the environmental burden of a product, organisation or system, they should draw on more encompassing tools such as life cycle assessments [31,68]. LCA is the only tool that enables to prevent environmental burden shifting, i.e. when decisions targeting the reduction of a specific environmental impact, e.g. climate change impacts, lead to increase in other nonetheless relevant environmental impacts, e.g. impacts on ecosystems and human health from toxic substance releases [68]. 
Another issue, rarely addressed, is the representativeness of the environmental concern by the respective footprint indicators. Figure 1 shows a mapping of the different footprints from Table 1 (colour-framed boxes) in relation to the impact pathways characterising the different environmental processes from the emission of pollutants and the use of resources to the damages to ecosystems and human health. Most footprints are observed to be defined at the early stage along the causeeffect chain and several of them are more inventory indicators than impact assessment indicators (e.g. land footprint, material footprint, phosphorus footprint). The environmental relevance of those indicators may therefore be questioned, particularly if one of the purposes of the footprints is to identify environmental hotspots, e.g. substance or resources largely contributing to the assessed area of concern.

With respect to their assessment methodologies, the different footprints can be divided in 3 groups: (i) those that are well established, e.g. ecological footprint or carbon footprint (benefitting from the IPCC works); (ii) those that are less methodologically-advanced, e.g. chemical footprint (only enabling assessment of impacts on freshwater ecotoxicity; still under development) or biodiversity footprint (limited coverage of causes of damages to species composition); and (iii) those that are missing, albeit needed to assess uncovered areas of concern (e.g. all damages to human health from particulate matter or chemical pollution). In an effort to build a consistent family of footprints, the development of existing and new footprinting indicators should therefore heavily draw on the knowledge accumulated within the LCIA field to characterise damages to ecosystems and human health from environmental interventions [31,33]. 
Laurent A., Owsianiak M., 2017. Potentials and limitations of footprints for gauging environmental sustainability. Current Opinion in Environmental Sustainability 25, 20-27. DOI: https://doi.org/10.1016/j.cosust.2017.04.003

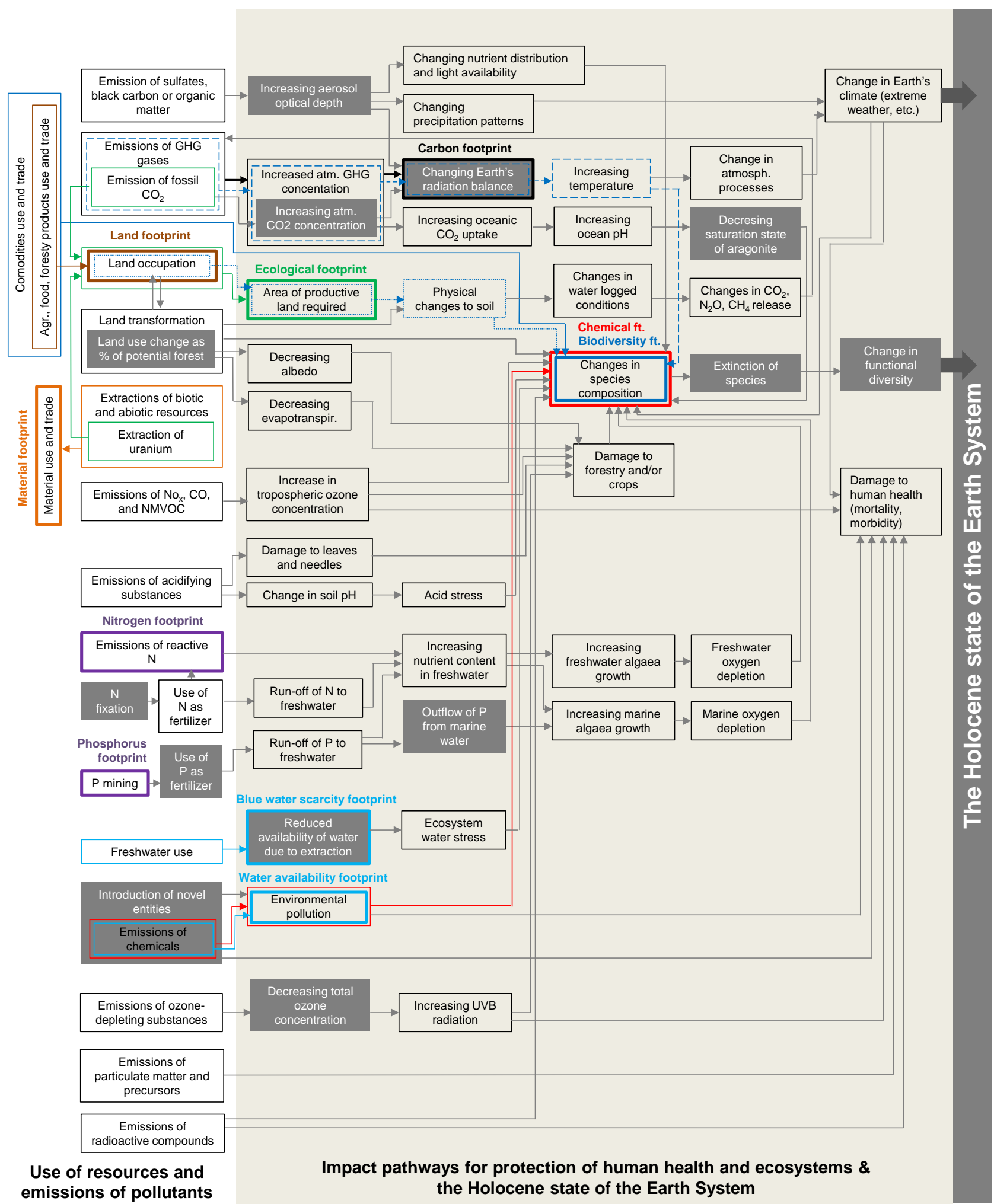

Figure 1. The footprints map in perspective with the environmental impact pathways covered in life cycle impact assessment (for damages to human health and ecosystems) and with the planetary boundaries reported in Steffen et al. [19]. The impact pathways are described by cause-effect chain mechanisms leading from pollutant emission or resource use (left side of figure) to impacts and damages to ecosystems and human health (right side of figure). Thus, the square boxes represent environmental processes along these cause-effect chains (in a simplified manner). Boxes with coloured frames (with indicated names) represent footprint indicators as positioned along the impact 
pathways. Grey boxes represent control variables of the planetary boundaries as positioned along the impact pathways, with linkage to the Holocene state of the Earth system. Note that not all environmental pressures or impacts covered in life cycle impact assessment and footprints have the potential to move the Earth system out of the Holocene state (e.g. damages to human health). The figure is inspired by Figure 1 in Ryberg et al. [70].

\section{Relevance of footprints' thresholds and calculation approaches}

Footprints have originally been designed to quantify the magnitude of the pressure on the environment without necessarily benchmarking the results against absolute limits or thresholds derived from ecological limits of the planet (e.g. finite resources, ecosystems’ carrying capacities) or science-based environmental sustainability targets. For example, a carbon footprint typically assesses the contribution of an entity to climate change impacts but it does not put the resulting score in perspective, whether high or not. To be useful in decision-making processes and informative contexts, it is important to make the link between the footprint score of an analysed system and the maximum allowed level of the environmental pressure captured by the footprint indicator (referred to as "footprint thresholds" in the following), above which the system is environmentally unsustainable in absolute terms. This link is determinant to enable fulfilling the output/input rule defining environmental sustainability (see introductive Section “On-going development of footprints”).

To estimate this state of absolute environmental sustainability, the concept of planetary boundaries (PB) can be used. PBs have been identified for a number of environmental processes, which are essential for maintaining the Earth System (ES) in a Holocene-like state, i.e. a 11700-year-long stable era, during which key biogeochemical and atmospheric parameters only fluctuated within relatively narrow range, thus allowing human societies to flourish [71]. In this setting, a planetary boundary is defined as a level above which there is a substantial and increasing risk that perturbation of the environmental process could lead to abrupt and irreversible change of ES state (Holocene-like). Using the PB framework to set footprint thresholds has been suggested [17], 
although a number of additional issues needs to be addressed to consistently set these thresholds and interpret footprint results in relation to them.

As observed in Figure 1, there is a general misalignment within the impact pathways between the position of these footprint indicators (colour-framed boxes) and the control variables of the PB framework (in grey boxes). Although land, nitrogen, phosphorus, water availability, biodiversity and chemical footprints are defined close to respective control variables from the PB framework, there is still a need for linking one another and/or consistently modelling the cause-effect chain mechanisms if the footprints and PB have to be integrated into a common framework. A simple example is the integration of a land footprint with the control variable of the land-system change $\mathrm{PB}$, which is defined as the remaining forest cover from the potential area of forest assuming no human land-cover change and which thus could easily be linked to a forest land footprint (see Figure 1), In the current setting, the development of an aligned assessment framework seems to be the most straightforward for carbon and water scarcity footprints because of their respective positions in relation to those of ES processes of climate change and freshwater use in the PB framework -see Figure 1.

Determining thresholds for climate change can however remain challenging. Fang et al. [17] in their framework for integrating environmental footprints and planetary boundaries used a global threshold for carbon footprint based on the 2-degree target (same as in ref. [1,72]). As argued by Fang et al. [17], this target has advantages over the PB defined at the level of either atmospheric concentration of $\mathrm{CO}_{2}$ or energy imbalance at top-of-atmosphere. However, its use leads to a resulting footprint threshold, which is not strictly aligned with the PB as the 2-degree target corresponds to the higher end of the uncertainty zone of the planetary boundary, i.e. $350-450 \mathrm{ppm}$ or $1-1-5 \mathrm{~W} / \mathrm{m}^{2}$ [73]. Hence, there is a risk of moving the ES out of the Holocene-like state when using a carbon footprint threshold aligned with the 2-degree target. For a direct match, the integration of any footprints with relevant PB should therefore consider the area of protection of the 
PB framework, i.e. the Holocene state of the ES, as a starting point for defining footprint thresholds [70]. Only in the case of freshwater use, a direct match already exists between the blue water scarcity footprint and the corresponding control variable of the PB (see Figure 1). Both have the same units and are based on the same (or nearly the same) underlying data and approaches to modelling, which make them aligned. At global scale, blue water use thresholds of $4000 \mathrm{~km} 3 / \mathrm{yr}$ (4000-6000 km³/yr; [19]) and 1100-4500 km³/yr (ref. [1,74]) have been proposed.

Finally, as can be observed in Figure 1, not all footprint thresholds relate to the PB framework. The PB framework thus ignores any interactions between human activities and impacts on human health. Therefore, material footprints, which may be linked to materials availability or scarcity, have no connection to the PB framework. Likewise, albeit not yet defined, footprints that would address environmental concerns linked to damages on human health (e.g. health damages caused by particulate matter emissions) would fall outside the scope of the planetary boundary concept. Other means of deriving footprint thresholds from ecological limits of the planet or more widely from science-based environmental sustainability targets are thus required.

\section{Conclusions and outlook}

Although footprints have gained increasing momentum in recent years, stakeholders should keep in mind that environmentally-related footprints have the main purpose to inform society and nontechnical stakeholders on specific environmental problems or areas of concern. As such, because of their relative simplicity and broad acceptance, they can be useful to sensitise different target audience to environmental issues and, for some of them like carbon footprint, to manage to some extent impacts that products, organisations or nations have on specific environmental issue. However, because of their narrow focus and their limitations in comprehensively covering the cause-effect chain of the environmental concern, they should not be used as stand-alone tools to 
assess and analyse total environmental burdens or environmental sustainability as a whole. For that purpose, tools like life cycle assessments should be used instead.

To strengthen their usefulness, footprint scores need to be benchmarked against absolute thresholds, indicating levels above which the assessed systems lead to environmentally-unsustainable states. Such consistent thresholds still need to be defined for many footprints. With the exception of the carbon footprint and the blue water scarcity footprint, links between existing footprints and PB framework are weak or irrelevant, and science-based sustainability targets should thus be developed to be used as footprint thresholds. Additional footprints could also be developed, matching the control variables of the PB framework (e.g. see ref. [70]) or specific areas of concerns not addressed by it (e.g. damages to human health). Finally, most scientific knowledge in addressing footprint thresholds is currently limited to a global perspective. Although the need for regionalisation of these has been recognised and efforts in this direction have emerged (see, e.g. ref. $[18,19,60])$, there are still many challenges left to derive footprint thresholds at the levels matching the assessed entities, e.g. individuals, product, organisation, industrial sector. Such developments are required to make present and future footprints consistently operational.

\section{References}

Papers of particular interest, published within the period of review, have been highlighted as:

- of special interest

•• of outstanding interest

\section{1.• Hoekstra, AY; Wiedmann TO: Humanity's unsustainable environmental footprint. Science 2014, 344:1114-1117.}

The authors provides a thorough and concise overview of footprint development and applications at the different system levels (product, company, goegraphical level), and propose maximum sustainable levels for a number of global footprints.

2. Rockstrom J, Steffen W, Noone K, Persson A, Chapin FS, Lambin EF, Lenton TM, Scheffer 
M, Folke C, Schellnhuber HJ, et al.: A safe operating space for humanity. Nature 2009, 461:472-475.

3. ICSU, ISSC: Review of the Sustainable Development Goals: The Science Perspective. International Council for Science (ICSU), Paris, FR, 2015.

4. Goodland R: The Concept of Environmental Sustainability. Annu. Rev. Ecol. Syst. 1995, 26:1-24.

5. Goodland R, Daly H: Environmental sustainability: Universal and non-negotiable. Ecol. Appl. 1996, 6:1002-1017.

6. Wackernagel M, Rees W: Our ecological footprint: reducing human impact on the earth. New Society Publishers, Philadelphia, PA, US, 1996.

7. Wackernagel M, Schulz NB, Deumling D, Linares AC, Jenkins M, Kapos V, Monfreda C, Loh J, Myers N, Norgaard R, et al.: Tracking the ecological overshoot of the human economy. Proc. Natl. Acad. Sci. U. S. A. 2002, 99:9266-71.

8. Monfreda, C., Wackernagel, M., Deumling D: Establishing national natural capital accounts based on detailed ecological footprint and biological capacity assessments. Land use policy 2004, 21:231-246.

9. World Business Council for Sustainable Development (WBCSD), World Resources Institute (WRI): A Corporate Accounting and Reporting Standard. GHG Protocol Standards. Revised edition. World Resources Institute and World Business Council for Sustainable Development, 2004.

10. Finkbeiner M: Carbon footprinting-opportunities and threats. Int. J. Life Cycle Assess. 2009, 14:91-94.

11. Aall C, Thorsen Norland I: The use of the ecological footprint in local politics and administration: results and implications from Norway. Local Environ. 2005, 10:159-172.

12. World Wide Fund for Nature (WWF): Living Planet Report. Risk and resilience in a new era. WWF International, Gland, CH, 2016.

13. Hoekstra AY, Chapagain AK, Aldaya MM, Mekonnen MM: The Water Footprint Assessment Manual : Setting the Global Standard. Water Footprint Network, Wahington, DC, US, 2011.

14. Fang K, Heijungs R, De Snoo GR: Theoretical exploration for the combination of the ecological, energy, carbon, and water footprints: Overview of a footprint family. Ecol. Indic. 2014, 36:508-518.

The authors review existing footprints, targetting the development of a footprint family that include complementary and operational indicators, and relate these to overall sustainability assessment.

15. Čuček L, Kleme JJ, Kravanja Z: A review of footprint analysis tools for monitoring impacts on sustainability. J. Clean. Prod. 2012, 34:9-20.

16. Fang K, Heijungs R: Investigating the inventory and characterization aspects of footprinting methods: Lessons for the classification and integration of footprints. $J$. Clean. Prod. 2015, 108:1028-1036.

17. Fang K, Heijungs R, De Snoo GR: Understanding the complementary linkages between environmental footprints and planetary boundaries in a footprint-boundary environmental sustainability assessment framework. Ecol. Econ. 2015, 114:218-226. 
The authors propose an environmental sustainability assessment framework integrating footprintsplanetary boundaries and highlight issues associated with boundary scaling, trade-offs between sustainability gaps and harmonization of metrics between footprints and planetary boundaries.

18. Fang K, Heijungs R, Duan Z, De Snoo GR: The environmental sustainability of nations:

Benchmarking the carbon, water and land footprints against allocated planetary boundaries. Sustain. 2015, 7:11285-11305.

19.• Steffen W, Richardson K, Rockström J, Cornell S, Fetzer I, Bennett E, Biggs R, Carpenter S: Planetary boundaries: Guiding human development on a changing planet. Science 2015, 347:6223.

The authors developed and updated the planetary boundaries framework, with particular focus on (i) revising the boundaries, also accounting for heterogenity at regional levels, and (ii) identifying core boundaries, which have the potential on their own to bring earth system into a new state.

20. International Organization for Standardization (ISO): Environmental management - Life Cycle Assessment - Requirements and guidelines (ISO 14044:2006). ISO: Geneva, CH, 2006.

21. Stoessel F, Juraske R, Pfister S, Hellweg S: Life cycle inventory and carbon and water foodprint of fruits and vegetables: Application to a swiss retailer. Environ. Sci. Technol. 2012, 46:3253-3262.

22. Goldstein B, Birkved M, Fernández J, Hauschild M: Surveying the Environmental Footprint of Urban Food Consumption. J. Ind. Ecol. 2016. DOI: 10.1111/jiec.12384

23. European Commission: Recommendation 2013/179/EU on the use of common methods to measure and communicate the life cycle environmental performance of products and organisations. Official Journal of the European Union. EC: Luxembourg, LU, 2013.

24. Hauschild MZ: Assessing environmental impacts in a life-cycle perspective. Environ. Sci. Technol. 2005, 39:81A-88A.

25.• Hellweg S, Mila i Canals L: Emerging approaches, challenges and opportunities in life cycle assessment. Science 2014, 344:1109-1113.

The authors provides a synthetic overview of the life cycle assessment methodology with respect to the current potentials and limitations of LCA for assessing environmental impacts of products and systems and its research needs for a better environmental decision-and policy-making support.

26. International Organization for Standardization (ISO): Environmental management - Water Footprint - Principles, requirements and guidelines (ISO 14046:2014). ISO: Geneva, CH, 2014.

27. International Organization for Standardization (ISO): Greenhouse gases - Parts 1-3 (ISO 14064:2006). ISO: Geneva, CH, 2006.

28. International Organization for Standardization (ISO): Carbon Footprint of Products - Parts 1-2 (ISO 14067:2013). ISO: Geneva, CH, 2013.

29. Boulay A, Hoekstra AY, Vionnet S: Complementarities of Water-Focused Life Cycle Assessment and Water Footprint Assessment. 2013, 47:11926-11927.

30. Ridoutt BG, Pfister S: Towards an Integrated Family of Footprint Indicators. J. Ind. Ecol. 2013, 17:337-339.

31. Ridoutt BG, Pfister S, Manzardo A, Bare J, Boulay AM, Cherubini F, Fantke P, Frischknecht R, Hauschild M, Henderson A, et al.: Area of concern: a new paradigm in life cycle assessment for the development of footprint metrics. Int. J. Life Cycle Assess. 2016, 
21:276-280.

The paper presents the outcome of a task force gathering experts in life cycle impact assessment anf footprint development, who recommend a universal footprint definitions and address develeopment of footprint metrics.

32. Fang K, Heijungs $\mathrm{R}$ : There is still room for a footprint family without a life cycle approach-comment on "Towards an integrated family of footprint indicators." J. Ind. Ecol. 2014, 18:71-72.

33. Fang K, Heijungs R: Rethinking the relationship between footprints and LCA. Environ. Sci. Technol. 2015, 49:10-11.

34. Jolliet O, Frischknecht R, Bare J, Boulay AM, Bulle C, Fantke P, Gheewala S, Hauschild M, Itsubo N, Margni M, et al.: Global guidance on environmental life cycle impact assessment indicators: Findings of the scoping phase. Int. J. Life Cycle Assess. 2014, 19:962-967.

35. Hertwich EG, Peters GP: The carbon footprint of nations - a global, trade-linked analysis. Environ. Sci. Technol. 2009, 43:6414-6420.

36. Tukker A, Bulavskaya T, Giljum S, de Koning A, Lutter S, Simas M, Stadler K, Wood R: The Global Resource Footprint of Nations: Carbon, water, land and materials embodied in trade and final consumption calculated with EXIOBASE 2.1.

Leiden/Delft/Vienna/Trondheim, 2014.

37. Lenzen M, Moran D, Kanemoto K, Foran B, Lobefaro L, Geschke A: International trade drives biodiversity threats in developing nations. Nature 2012, 486:109-112.

38. Moran DD, Kanemoto K: Identifying the Species Threat Hotspots from Global Supply Chains. 2016, DOI: 10.1101/076869.

39. United Nations: Kyoto Protocol To the United Nations Framework Convention on Climate Change. UNFCCC, Bonn, DE, 1998.

40. Huijbregts MAJ, Hellweg S, Frischknecht R, Hungerbühler K, Hendriks AJ: Ecological footprint accounting in the life cycle assessment of products. Ecol. Econ. 2008, 64:798807.

41. Global Footprint Network: Ecological Footprint Standards 2009. Global Footprint Network Oakland, CA, US, 2009.

42. Galli A, Giampietro M, Goldfinger S, Lazarus E, Lin D, Saltelli A, Wackernagel M, Müller F: Questioning the Ecological Footprint. Ecol. Indic. 2016, 69:224-232.

43. World Wide Fund for Nature (WWF): Ecological footprints: A guide for local authorities. WWF United Kingdom, Surrey, UK, 2002.

44. Pfister S, Koehler A, Hellweg S: Assessing the Environental Impact of Freshwater Consumption in Life Cycle Assessment. Environ. Sci. Technol. 2009, 43:4098-4104.

45. Boulay A-M, Bulle C, Bayart, J-B, Deschênes L, Margni M: Regional Characterization of Freshwater Use in LCA: Modeling Direct Impacts on Human Health. Environ. Sci. Technol. 2011, 45:8948-8957.

46. Scherer L, Pfister S: Global Biodiversity Loss by Freshwater Consumption and Eutrophication from Swiss Food Consumption. Environ. Sci. Technol. 2016, 50:70197028.

47. Kounina A, Margni M, Bayart J-B, Boulay A-M, Berger M, Bulle C, Frischknecht R, 
Koehler A, Mila i Canals L, Motoshita M, et al.: Review of methods addressing freshwater use in life cycle inventory and impact assessment. Int. J. Life Cycle Assess. 2013, 18:707721.

48. Feng K, Chapagain A, Suh S, Pfister S, Hubacek K: Comparison of Bottom-Up and TopDown Approaches To Calculating the Water Footprints of Nations. Econ. Syst. Res. 2011, 23:371-385.

49. Boulay A-M, Motoshita M, Pfister S, Bulle C, Muñoz I, Franceschini H, Margni M:

Analysis of water use impact assessment methods (part A): evaluation of modeling choices based on a quantitative comparison of scarcity and human health indicators. Int. J. Life Cycle Assess. 2015, 20:139-160.

50. Boulay A-M, Bayart JB, Bulle C, Franceschini H, Motoshita M, Muñoz I, Pfister S, Margni M: Analysis of water use impact assessment methods (part B): applicability for water footprinting and decision making with a laundry case study. Int. J. Life Cycle Assess. 2015, 20:865-879.

51. Boulay A-M, Bare J, De Camillis C, Döll P, Gassert F, Gerten D, Humbert S, Inaba A, Itsubo $\mathrm{N}$, Lemoine $\mathrm{Y}$, et al.: Consensus building on the development of a stress-based indicator for LCA-based impact assessment of water consumption: outcome of the expert workshops. Int. J. Life Cycle Assess. 2015, 20:577-583.

52. Pfister S, Ridoutt BG: Water footprint: Pitfalls on common ground. Environ. Sci. Technol. 2014, 48:4.

53. Wiedmann TO, Schandl H, Lenzen M, Moran D, Suh S, West J, Kanemoto K: The material footprint of nations. Proc. Natl. Acad. Sci. U.S.A. 2015, 112:6271-6276.

54. Huysman S, Schaubroeck T, Dewulf J: Quantification of spatially differentiated resource footprints for products and services through a macro-economic and thermodynamic approach. Environ. Sci. Technol. 2014, 48:9709-9716.

55. Shibata H, Galloway JN, Leach AM, Cattaneo LR, Noll LC, Erisman JW, Gu B, Liang X, Hayashi K, Ma L, et al.: Nitrogen footprints: Regional realities and options to reduce nitrogen loss to the environment. AMBIO A J. Hum. Environ. 2016, DOI:10.1007/s13280016-0815-4.

56. Galloway JN, Winiwarter W, Leip A, Leach AM, Bleeker A, Erisman JW: Nitrogen footprints: past, present and future. Environ. Res. Lett. 2014, 9:115003.

57. Grönman K, Ypyä J, Virtanen Y, Kurppa S, Soukka R, Seuri P, Finér A, Linnanen L: Nutrient footprint as a tool to evaluate the nutrient balance of a food chain. J. Clean. Prod. 2016, 112:2429-2440.

58. Metson GS, Bennett EM, Elser JJ: The role of diet in phosphorus demand. Environ. Res. Lett. 2012, 7:44043.

59. Metson GS, Cordell D, Ridoutt B: Potential Impact of Dietary Choices on Phosphorus Recycling and Global Phosphorus Footprints: The Case of the Average Australian City. Front. Nutr. 2016, 3:35.

60. Zijp MC, Posthuma L, Van De Meent D: Definition and applications of a versatile chemical pollution footprint methodology. Environ. Sci. Technol. 2014, 48:10588-10597.

61. Bjørn A, Diamond M, Birkved M, Hauschild MZ: Chemical footprint method for improved communication of freshwater ecotoxicity impacts in the context of ecological limits. Environ. Sci. Technol. 2014, 48:13253-13262. 
62. Posthuma L, Bjørn A, Zijp MC, Birkved M, Diamond ML, Hauschild MZ, Huijbregts MAJ, Mulder C, Van De Meent D: Chemical footprints: Thin boundaries support environmental quality management. Environ. Sci. Technol. 2014, 48:13025-13026.

63. Sala S, Goralczyk M: Chemical footprint: a methodological framework for bridging life cycle assessment and planetary boundaries for chemical pollution. Integr. Environ. Assess. Manag. 2013, 9:623-32.

64. Hanafiah MM, Hendriks AJ, Huijbregts MAJ: Comparing the ecological footprint with the biodiversity footprint of products. J. Clean. Prod. 2012, 37:107-114.

65. Moran D, Petersone M, Verones F: On the suitability of input-output analysis for calculating product-specific biodiversity footprints. Ecol. Indic. 2016, 60:192-201.

66. De Benedetto L, Klemeš J: The Environmental Performance Strategy Map: an integrated LCA approach to support the strategic decision-making process. J. Clean. Prod. 2009, 17:900-906.

67. British Standards Institution: PAS 2050:2011 - Specification for the Assessment of the Life Cycle Greenhouse Gas Emissions of Goods and Services. BSI: London, UK, 2011.

68. Laurent A, Olsen SI, Hauschild MZ: Limitations of Carbon Footprint as Indicator of Environmental Sustainability. Environ. Sci. Technol. 2012, 46:4100-4108.

69.• Steinmann ZJN, Schipper AM, Hauck M, Huijbregts MAJ: How Many Environmental Impact Indicators Are Needed in the Evaluation of Product Life Cycles? Environ. Sci. Technol. 2016, 50:3913-3919.

The authors recognize that the multitude of indicators for assessing environmental impacts is not adapted to decision-making and explore the mutual correlations of 135 indicators to remove redundant ones, eventually shortlisting a small key set for assessing product life cycles.

70.• Ryberg MW, Owsianiak M, Richardson K, Hauschild MZ: Challenges in implementing a Planetary Boundaries based Life-Cycle Impact Assessment methodology. J. Clean. Prod. 2016, 139:450-459.

The authors identified key challenges in the development of a new life cycle impact assessment (LCIA) methodology for linking human activities to planetary boundaries, including the integration of the Earth System processes and their control variables within impact categories of the LCIA framework.

71. Rockstrom J, Steffen W, Noone K, Persson A, Chapin FS, Lambin E, Lenton TM, Scheffer M, Folke C, Schellnhuber HJ, et al.: Planetary Boundaries: Exploring the Safe Operating Space for Humanity. Ecol. Soc. 2009, 14, 32.

72. UNEP: The Emissions Gap Report 2012 - A UNEP Synthesis Report. UNEP, Nairobi, 2012.

73. Hansen J, Sato M, Kharecha P, Beerling D, Berner R, Masson-Delmotte V, Pagani M, Raymo M, Royer DL, Zachos JC: Target Atmospheric CO2: Where Should Humanity Aim? Open Atmos. Sci. J. 2008, 2:217-231.

74. Gerten D, Hoff H, Rockström J, Jägermeyr J, Kummu M, Pastor AV: Towards a revised planetary boundary for consumptive freshwater use: Role of environmental flow requirements. Curr. Opin. Environ. Sustain. 2013, 5:551-558. 